\title{
Kinship as a Social Capital in Rural Development: An Anthropological Perspective
}

Rudra Aryal

\begin{abstract}
This paper is the study of institutional and organizational aspects of the management system of a community based micro hydropower. It mainly focuses on the role of kinship as well as social capital for the sustainability of micro hydropower management. However, social capital has been analyzed as one of the fundamental sources of kinship organization. This study also emphasizes on the social transformation that is only possible with an effective social mobilization and reliable institutional sources. An organized form of management system for micro hydro is functioning continuously due to the consistent engagement of community, proper mobilization of groups/institutions and institutional guidance, where social and cultural substances are primarily embedded. Ethnographic fieldwork was the principal data collection method. Both direct and indirect participant observations were used to garner the substantial amount of data. In-depth nature of semistructured interviews on various social, structural and cultural aspects was used to conduct the key interviews. To make the representative units inclusive, twenty people were purposively selected for key informant interviews including male, female and from the various occupation status. The related structural issues as well as regarding the entire management system of micro hydropower were probed through the informal interviews and group discussions to enhance the ethnographic data.
\end{abstract}

Keywords: kinship, social capital, community, institutional culture, micro hydropower

\section{Introduction}

The principal objective of this paper is to analyze and discuss the role of social network of kinship for the management of community based micro hydropower, which is one of the significant alternative energy sources for the community development. The affinal kin between two clans of Jaisi Brahman of Pokhari village is produced a normative form of social subjectivities, and these social subjectivities have galvanized the existing social capital in effective positioning for the sustainability of micro hydropower. In other words, this study is to assess primarily the sustainability of development practice in a community level by examining the existing social capital in the kinship network. This paper also suggests that the micro hydropower, as a human made energy resource, can also be treated as a common property regime (CPR) where institutional as well as social arrangement regulating the resource preservation and sustainable resource consumption. Theoretically, a certain group or class has the rights only to use those resources by managing them within the CPR framework, where equally enabling self-organized group by the resource users to manage collectively the resources (see Ciriacy-Wantrup and Bishop 1975; Bromley 1986 and 1990; Ostrom 1990 and 2000; McKean 1996; and Bruce 1999).

Based on ethnographic data, this paper argues that though the primary condition of a sustainable resource management requires institutional arrangements of common property regime (CPR), there must be a well-off environment of institutional culture, which is regulated through the traditional and non-traditional social institutions. Principally, the institutions of the family, marriage, kinship and decent systems are the basic social building blocks in any society (Kottak, 2004) and these institutions whose members and their social behavior as well as social and institutional patterns and other various activities has been analyzed in this study. This kind of social scenario helps to understand the social capital and institutional culture. Hence, the state of well-off institutional culture galvanizes the social capital in highly manner for the contribution of the sustainability of "'mutual benefits and collective actions in relation to the resource management system" (Uphoff, 1996). Therefore, it has revealed a number of significant points of anthropological issues for the effectiveness of development structures by focusing on socio-cultural dimensions of institutional culture.

For the study of anthropology of community development, I have selected micro hydropower management that signifies an alternative way of community/ rural development. Usually, the community and its various formal-informal social institutions are responsible for the sustainable management of micro hydropower that is disclosed through this paper. Although the key part of this paper is self-organized/self-governed micro hydropower management system based on kinship system and various forms of capital, paper also examines over the development practices and community transformation through the 
normative/cognitive variables embedded in the sociocultural capital of the community.

\section{Research Method}

In this research, I have used substantial amount of qualitative data by conducting the ethnographic fieldwork in the ChaunriKhola-I Micro Hydropower of Pokhari village, Kavrepalanchowk district. This paper is the outcome of my MPhil study, whereas fieldwork was conducted between January and February 2015. All the households (total sixty-four households) in Pokhari are beneficiaries of twenty-two kilo watt electricity produced by of ChaunriKhola-I Micro Hydropower (MHP).

In this research, participant observations and key informant interviews were conducted throughout ethnographic work as the principal data collection tools. In total, twenty individuals from various sectors such as school's teachers, key persons of ChaunriKhola-I MHP cooperative, chiefs of MHP management committee, social workers and political leaders were selected for key informant interview. In-depth nature of semi-structured interview on various social and cultural aspects such as behaviors, rules, customs, norms and values were deployed to fulfill the key interviews. Issues were probing through the informal conversational interviews with focal persons and household heads to enhance the ethnographic data. In addition to enhancing, as for the supplementary data collection strategies, focus group discussions, audio and video recordings were also used as enhanced techniques to make a study more rigorous that is already set up as an ethnographer (LeCompte and Schesnul, 1999). Besides, household survey was also conducted to furnish quantitative information of economic level. For this, I did purposively select ward number two and some parts of ward number nine as well. Pokhari village covers these two wards. To make the representative units inclusive, a sample size was purposively selected with fifty households from Pokhari settlement including Jaisi Brahmans, Chhetris, Janajati and Dalit. Among fifty households, Jaisi Brahmans (thirty-seven households), were at the highest number of populations in the Pokhari. With eleven households of Chhetris are selected and rest households were of a Dalit and a Janajati.

\section{Pokhari Village: An Organized and Homogenous Structure}

The state of homogeneity is an embedded factor of the Pokhari community that has highly influenced on the enduring interconnections, interdependent and solidarity between the socio-cultural practices. This section has exposed various points in terms of homogeneity. Here homogeneity deals with uniformity practices of social subjectivities (i.e. normative arrangement) of the community produced by both marriage practice and kinship system mainly. It is necessary to know that the foundation of community development as well as micro hydropower management system are directly-indirectly associated with these two dependent variables which uphold the existing social capital stalwartly for the overall management system of human made resource, i.e. micro hydropower. For this, I mostly emphasized on "the unity and homogeneity of bounded cultural units" (Barnard and Spencer, 2010, p. 155).

Many anthropologists have talked about social homogeneity. Fortes defines that any peoples of same category have the similar nature of customary usages and beliefs that are assembling each other as per their statuses (Fortes, 1970). The ethnographic realities are presented here to realize the underpinning issues that are ultimately assembled and shaped in the solo identity, as in the name of homogeneous Pokhari community. The elementary level of marriage practice is one of the major backgrounds of ethnographic reality of this study.

As mentioned above, Jaisi Brahmans are socially domineering groups of that community. It also seems like caste homogeneity; both Jaisi Brahmans and Chhetris are at the apex respectively in caste hierarchy. The similar caste category of population is not only a reason of homogeneity of Pokhari but also the commonly shared several socio-cultural behaviors and practices that reflect in the management system of micro hydropower and MHP cooperative-a micro finance institution. It means there are other numerous structural, cognitive or normative components that are embodied homogeneously.

Regarding Jaisi Brahman, two types of Brahmans are existed in Nepal, namely, Upadhaya and Jaisi. Bennett (1983, p. 11) writes 'at the apex of the caste hierarchy are the Upadhaya Brahmans whereas Jaisis are known as lower than that of the Upadhaya Brahmans in caste hierarchy'. She clarifies that 'the offspring of a union between an Upadhaya Brahman man and a Brahman widow or divorcee are known as Jaisi Brahman' (ibid).

This paper ignores the issues of caste structure and behaviors because Pokhari does not have any capacity in the comparative study of caste hierarchy. Hence, I termed Pokhari-the homogeneous society based on the kinship organization and well-off structure of social capital. Many studies related to social and cultural anthropology have probed about the structural issues of particular societies or tribal groups. This study also does not exclude the structural issues that mainly indicate the social institutions i.e. marriage, family and kinship. Fortes also concerns on the simple and complex tribal societies on the basis of structural domains. In his experiences from the tribal societies that structural domains tend to be fused in simple societies whereas in complex societies the structural domains and differentiated are numerous (Fortes, 1970). Structural domains of Pokhari community is not a simple, it is a complex one. However, the structural issues such as marriage system, kinship organization, social capital, internal-external institutional practices and so on are collated in a single pillar, i.e. social homogeneity.

The ancestors of the two family groups of Pokhari, Chaulagain and Gautam of Jaisi Brahman have been residing in Pokhari for more than two hundred years. A number of old aged persons told me 'it is probably 
from the time of king Prithivi Narayan Shah'. Currently, the families of these two groups are the ninth to tenthgeneration descendants of their ancestors. Many older informants had a common axiom. They expressed during the conversation that 'Pokhari had the history of both of the Gautams and Chaulagains to have migrated at the same time from west-Nepal'. In course of time, they started marriage between each other; still the practice has been continuing. To be more specific, Gautams get married only to Chaulagains and Chaulagains get married only to Gautams. On this point, according to an old age Guru 'such kind of marriage practice has been running since nine to ten generations and probably much longer, but this is not fair religiously and culturally. It is completely socially and religiously prohibited in marriage between the maiti-mawali relationship'.

On the ground of above given social structural facts, both have a symbiotic social relationship, it means they have been practicing a mutualistic symbiosis in social relationships for centuries. They are the most interconnected within specific socio-cultural structure made by same-caste-category between the patrilineal kin and matrilineal kin. In other words, the kinship structure and social capital of Pokhari community have created a web of social relationships in the same structural principles built with both the consanguineal and affinal ancestors of Gautams and Chaulagains. As a result, social capital of Pokhari village has been established as one of the integral part of social safeguard. Fortes states the societies in which the same structural principles and moral axioms work at all level for the social structure, i.e. the organic society (Fortes, 1949).

From the above viewpoints, it is clear that the foundation of the family structure of Pokhari village is a distinctive one whose social values benefitted obviously upon the social and development institutions (family, marriage, small saving groups, micro hydropower cooperative, NGOs, etc.). For instance, if an individual goes to someone's home in his/her own community, s/ he is in the relative's home. Similarly, if two people of Pokhari encountered each other in the roadway, there is no doubt that they are the relatives. They have obviously either a patrilineal or matrilineal kin relationship. Such interconnected structure of web of kin has influenced the social, cultural and economic factor of Pokhari. To have the benefit to the society indicates the benefit to the 'manner of bond' existing between people. This bonding manner has carried various meanings with regard to social-welfare and community development of Pokhari. Symbolically, bonding manner is often observed as the source of the individual, familial and communal way of life. For that reason, this bond is so potent that every members of the community feel secure with it.

The study and analysis of this 'bond' is made from another viewpoint. For instance, the significant impacts of kinship bond had been occurred over the social capital and the development activities. The examination of the state of such social capital of Pokhari is based on the various normative components. Viz., social solidarity/ unity, friendship, brotherhood, sisterhood, reciprocity, generosity, altruism, trust, etc. These are the normative form of social formation of Pokhari village. Furthermore, making decision for any social actions is the best for Pokhari because decision does not take more time with less hostility. On the other hand, resource management system for the community development, collective action activity is another key of close social interrelationship (Ostrom, 2000 and Paxton, 2002). The close or uniform social relationships and social capital are an integral part in promoting collective practices/behaviors. Many scholars describe that bonding social capital always defined as a relationships of trust, unity, reciprocity, brotherhood, fondness, etc., that always exist between individuals. Such kind of relationships always promotes and sustains the collective action in a homogeneous manner. Therefore, based on these findings, I conclude that the social structure of Pokhari is a homogeneous as well as harmonized.

The above given facts are mainly the normative positions of Pokhari but it is not enough to mention in terms of the cohesive and organized Pokhari. One more force is equally responsible of creating an organized and homogeneous Pokhari community. It is about developing organizational culture, which I am going to discuss now.

\section{Story of Building Organization and a Process of Micro Hydropower}

Just six month before of the construction of micro hydropower scheme, a development agency, an NGO, enters as a supplementary force i.e. Rural Electrification Development Programme (REDP). Two representatives of the rural program of REDP, Mukti Taujale and Dilip Sharma were the first persons to come to Pokhari in 1997. They had some programmes related to social mobilization planned by REDP. Most of the informants in the study shared that, prior to the establishment of micro hydropower; REDP had launched the social mobilization programs according to its plan from August 21, 1997. They worked according to the idea of NGO. Most of the NGOs working in Nepal have prioritized in four successive areas which include "relief and welfare, community development, sustainable systems development, and people's movements" (Korten, 1990). Regarding the development contributions of these two persons can be classified into two phases that has inspired for changing the image of Pokhari village. The first, formation of preliminary small social groups/ organizations and their mobilization; the second, building up an improved social environment to take the speed of establishment of micro hydropower project. At least, the NGOs and its staff have more ideas to work in the development domains within the criteria of effective and reliable manner because of their lot of experiences are significant to some extent in their development practices at the remote areas or underprivileged community. The staffs of NGOs, having a rapport with rural people and their needs and also the knowledge about local resources, are able to secure the participation of the poor in devising and implementing locally relevant projects (Suar, Hota 
and Sinha, 2006, p. 163). This is the reasons why I gave the exclusive emphasis to them in this study.

As the very first step of the initiative, REDP personnel created the samuhas (groups). Initially six samuhas including three male groups and three female groups were formed. One male and one female from each household were selected for the gender equality. During my field work, many people shared that the main challenges in the process of increasing the consciousness are to persuade the villagers about the result of new project. Instead, a great challenge is to create an environment of trust overcoming the distrust. The groups were encouraged to be mobilized based on six mantras (key hymns) as per the REDP plan. According to micro hydropower profile, there was mentioned those six mantras - organization, saving, skill, technology, empowerment and environment protection. These six mantras helped accelerate the speed of group mobilization for capacity development, and learning skill oriented works. The strategies of mantras gradually worked with the people friendly and improve-oriented. It was necessary too as the social relationship between the inhabitants was not broad, even the community is a web of kinship relationships.

Within the six months, the environment of trust was created and some positive changes occurred among the local people. Even the hesitating persons were also seen very open and fearless. Women were also found to be capable of to delivering long speeches in the group's meeting. Greeting system instituted and it gradually went common in weekly and monthly meeting. Old aged people told that discipline was taught in the meeting for informal conversation too. People were now on the way to find the solution of their household problems in the meeting openly. The unequal behavior between spouses, for instance, dominating nature of the husbands over the wives is one of them.

The entire activities of the samuhas had to establish a notion of the community changes and transformations among the social structure. These all initiatives are the foundational activities for the establishment and operation of micro hydropower from ChaunriKhola, which constantly flowing at the lower part of the Pokhari. Similarly, various issues like problems of property rights, women's role in participation in decision-making processes, empowerment of women were gradually solved. Sustainability of MHP management system was another mission of such efforts. It can be supposed that the NGO staffs are turned out to be the landmark for the fundamental transformation of the Pokhari community.

In the past years, more than 30 paani ghattas (traditional water mills) were in existence in ChaunriKhola. A study has reported that micro hydro systems can be locally managed and operated with simple trained local people, and the organization and management cost are lower than for the other energy systems while the adverse environmental effects are minimal (CRT/N, 2005). Since the micro hydropower projects are wider in various respects than ghattas, they are supervised, managed and operated by communities as a whole. Hence, the entire villagers of
Pokhari were also taught about the preliminary theoretical idea about the production of electricity.

In a meantime, villagers had no belief that electricity could be produced from ChaunriKhola. It was out of their imagination. Their thinking was that ChaunriKhola did not have enough water to produce electricity, and they did not have enough money to donate for the programme. 'Electricity is not much beneficial to us; it is the sheer waste of money while paying the fee', villagers used to say. These kinds of distrusts regarding the hydropower production had completely veiled the villagers. To persuade the villagers, programme leaders decided to take them on the observation of any hydropower. They found a similar kind of water flow like ChunriKhola and geographical settlement like Pokhari. For that, thirty villagers were taken to visit Tinau Khola, situated in Syanja district, micro hydropower and the nearby settlements for four days in June 1997. Villagers were spellbound with the development progress made with the local people on hydroelectricity in the place similar to them geographically. Village there was lighted at night with electricity, they used to watch TV and play radio. As a result, the visitors from Pokhari were encouraged to do alike. They shared what they had seen with the neighboring villagers after they returned to the village. Then, all the inhabitants of Pokhari were ready to work for constructing the micro hydropower.

From the above historical facts, a question can be raised. Surprisingly, how fast Pokhari was transformed in an organized form just within the six months of period? The unseen reality was the role of social capital produced by the web of kinship; however, the existing social capital was passive before the formation of samuha. When two forces, programmes of REDP and the dream of micro hydropower with two veteran NGO workers, entered the community, kinship found its real quality over the social capital. These two forces will again be discussed in later section.

The empirical evidences have proved that Pokhari transformed over time from the ordinary Pokhari to absolute organized Pokhari. And so, that qualitative standards centralized into the norms and values among the community, which proves Pokhari as a self-organized community during my ethnographic period. In brief, there was a noticeable progress in the community due to the bilateral and symbiotic relationship between kinship and social capital.

\section{Marriage Practice and the Social Production}

Given the following empirical facts are important to know the unique marriage system or practices found in the high caste Jaisi Brahman. It seems that it might also be irrelevant. However, during my ethnographic work, I found a kinship network of Pokhari was a mainstay of micro hydropower development. The study of micro hydropower development of Pokhari village would be incomplete if marriage system is not included. As I said already, the foundational components of the micro 
hydropower development/management were marriage, kinship and social capital, which are the units support to build an organized community. These three were the intrastructured institutions found in the Pokhari community. The concepts of social institution both kinship and marriage are always correlated each other. So that marriage practice prevalent in the community is incorporated here.

The marriage system adopted in high caste Brahmans, between Gautams and Chaulagains, of Pokhari has a special significance due to the unique and separate practice. This is, in fact, a cross-cousin marriage practice adopting by the high caste hill Brahmans. In other words, this is a marriage system between only the matrilineal and patrilineal descents i.e. also a marriage system between consanguineal and affinal members. This kind of marriage practice cannot often be found in the Brahmans community of other parts of Nepal because it violates the traditional marriage rules, so this is a unique and exceptional case. However, in Nepal cross-cousin marriage practice is widely prevalent in other ethnic groups such as Gurung, Thakali, Magar and Tamang (Bista, 2002).

There are normally two rules that should be followed by high caste Brahmans or Hindus; even they are Chhetris, Newars and other low castes as well. First, the general norms and values or rule of Nepali Brahmans or Hindus for marriage is that the boy and girl should not have direct blood relation, i.e. they should not share gotra (same clan). Bennett mentions 'because of the conceptual importance of gotra as a "spiritual" descent group, it is considered a sin to knowingly marry within one's own gotra' (Bennett, 1983:17). Secondly, Nepali Brahman community and Hinduism both have forbidden the marriage with someone of maitithar (surname/clan of a women's natal home).

However, in the marriage practice of Pokhari, the majorities (Gautams and Chaulagains) have been violating the second rule, although that is strictly prohibited and is termed as a social taboo as well. According to the old aged informants 'such practice is prevalent here from about ten generations'. It seems like this is a case of exchange marriage practice as well which is prevailing among the consanguinity and affinity.

In a house, where I lived, that showed the entire male youths of all six generations got married only with someone of mawali relatives (mawali refers to mother's brother's home). In other words, the maiti of every generations (the then and now) of daughters-in-law and the mawali of all generation of hers fathers-in-law were of same thar(surname).On the other, daughters of every generation of the family were sent to their mawali relativesas a daughter-in-law. Moreover, the familial and social relationship of maiti, mawali and ghar (here it denotes 'husband's house') are always in the core and peripheral kin network between affinal and consanguinal people. Likewise, the daughter-in-law can certainly be the didi-bahini (sisters) or bhanji (sisters' daughter i.e. niece or cousin) of the father-in-law, and the daughter-in-law can certainly be the didi-bahini or bhanji of her mother-in-law. In this situation, a girl has high respect like that of a bhanji while unmarried. When she turns into a daughter-in-law of the same people after marriage and respect to her decreases as her status is lower than that of niece. Responsibilities multiply after she becomes a daughter-in-law. She would get dakshina (gifts/money given to individuals of the house on ceremonial occasions) while receiving tika (a mark of blessing placed on the forehead) in unmarried life. But when she becomes a daughter-in-law (who was cousin/ niece) would be deprived of it. It clarifies that family network/relation couldn't get chance to be more wider. Rather they have in a position of the social and family contraction. They tightly tied up with a single linear family network, which influences the social opportunities in the form of social capital. For that reason, the local-socialrelationship created by that marital kinship is stronger. It means that its relation is seen on social capital. Hence, the overall Pokhari community has structured with these two family groups. There is no doubt then the impact of family group of both consanguineal and affinal lies upon social organs and activities.

Meanwhile, I met with an old aged Sanskrit expert, having various facts about the history of that matrilaterial cross cousin marriage practice. He shared his knowledge of that marriage practice in these words:

We feel shameful outside the village if the subject matter is about our marriage practice. Other societies call us 'pataki' (sinner people). They used to tell us what kinds of people we are? We get into trouble when it comes to the conversation about our marriage practice. The conversation on this subject could not be always avoided. On the other hand, we should feel shameful or disgraced if we tell the real facts. It has made others not to have marital relationship with us and we are compelled to follow our tradition. There is no other option or alternative for us. (Informal talking: February 13, 2015).

This was the common problem of all the adults of Pokhari. The youngsters also opined that this practice must be stopped. Otherwise, they would also see it continued in their generations. It was a great challenge for the Gautams and Chaulagains of Pokhari because it is well practiced even by the educated and well-off people. All of them accused the preceding generations as its cause. So, the people of older generation were found to be most worried about it as all accuse them of being passive towards putting an end to the practice. The younger generations often blamed their parents and grandparents for not stopping it in time to set them free from such unwanted impure relation. In response to them, the older people acknowledged that other family or clans, sub-clans, hesitated or even rejected to have marital relationship with them due to socially and religiously unacceptable marital relation. Secondly, they pointed towards the economic problem. After the younger generations found the satisfactory answer from their ancestors, they pledged to end it up from their children's marriage.

The indirect reality, even the marriage system had the impact on the role played by the social institutions and community in the management of micro hydropower. This is a strong position of marital harmony as a key unit of overall family relations. Moreover, such kind of key 
unit reproduces other various similar units in social level as in the form of social capital because marital harmony has become a key value of any kinship organization. In every society, marriage system becomes a foundational source of other social institutions; one of them is kinship organization that always galvanizes the social capital for the social properness.

\section{Kinship Organization: The Strongest Source of Social Cohesion}

This section also presents conceptual and empirical discussions about the role of kinship organization over the social relationship of Pokhari community. As assumed by Radcliffe-Brown regarding the kinship is "the source of social cohesion" (as cited in Schneider, 1984 p. 49). This social cohesion can be found in any family groups or community who share common norms, values and culture for mutual benefit within a kin system. Pokhari community is fit for this notion. This review considers kinship as social phenomena to build the self-regulating principles for the various social institutions. Besides, a review is made on how the kinship system creates an environment of a source of social unity, with the help of normative form of social capitals mainly, of a particular community or groups for their social and development benefits. For this reason, it is most necessary to show in relation to the social unity and their reciprocal relationship between individual-familial and social environment of Pokhari.

The state of kinship structure of Pokhari is similar to the 'theory of alliance' that is coined by Claude Levi-Strauss in his famous book 'The Elementary Structures of Kinship' (1949). The key emphasis of this theory is to deals with cross-cousin marriage, where the development of alliances between groups through the exchange marriage of women is one of the fundamental facts of kinship study (see LeviStrauss, 1949). He explains kinship through the structural assumption that all kinship systems are always in the form of elementary structures. In his kinship study, the mother's brother is an important member because the relationship between a man and his maternal uncle is crucial for the marriage purpose. Such kind of relationship is prevalent in the Pokhari, which is also known as symmetric exchange of marriage practice. In the symmetric case of Levi-Strauss, he explains women from group A marry men from group B, and conversely B's women marry A's men. In the case of Pokhari community, group A can signify to Gautam family and group B can signify to Chaulagain family.

In this manner, Pokhari has adopted both patrilateral i.e. fathers' sides and matrilateral i.e. mothers' sides cross cousin marriage system. Concisely, a bilateral cross-cousin marriage practice similar to the stated family groups has adopted.

Although this practice is uncommon in the case of Pokhari, Kinship system built by marriage practice has positively affected over the social system and everyday life of the community. However, the earlier studies of kinship done by many anthropologists had focused on biological importance only but later Schneider showed a great concern from his wider study on the social relationship and social interaction (Schneider, 1984). Over the years, kinship related conceptual ideas are widely intertwined with the social phenomena. This paper does not completely emphasize on biological or genetic relatedness of kinship system. Rivers has the opinion in this regard that kinship should be studied not only from the perspective of blood relationship or genealogy but also from the perspective of social convention, social procedure, terms of relationship and social function (Rivers, 1968).

As such, this paper's kinship notions are largely directed to the Schneider's viewpoints. As for him the kinship sources have been revolving around the social relationship and behavior for the social changes (1984). However, the spirit of the symbolic meaning of the proverb- 'blood is thicker than water' (Schneider, 1984) is also somewhat appropriate in this study. This symbolic proverb is most relevant to the social homogeneity caused by kinship structure. However, Schneider does not fully support this spirit in his kinship account. In general, this paper has also an assumption based on the social relationship directed by kinship organization, where any individuals or groups of individuals fulfill the responsibility of social roles in an organized way by joining in the various social groups.

Meanwhile, Schneider takes as fact, for the primitive societies, kinship has an organizing principle or idiom of most groups and most social relations (Schneider, 1984). Social relations are always created and constituted by the process of interaction, or 'doing' (Schneider, 1984, p. 165). So Schneider's critique is widely accepted in the anthropological study of kinship due to his emphasizing on social relationships and interactions, which have marked a turning point (Schweitzer, 2000 and Carsten, 2000). The latest anthropological tradition of kinship studies have emphasized on the social processes. This paper has also shown the kinship influences over the social process, which is a root cause for the particular social behavior. There is a micro hydropower has been running for a decade and overall safeguarding process of micro hydro existed that is possible only because of self-organized Pokhari community. Such kind of social influence occurs only when more than two individuals or family groups are expressing and behaving in a social context of interaction.

Similarly, in kinship, kin folks are exhibited by altruism, love and generosity to one another, and strictly equivalent returns from one another are not demanded (Fortes, 1969). In other words, the roles of kinship institution are found fulfilled only through social property. Undoubtedly, Pokhari is a community with the full support of social capital. Whatever benefits are arisen in the management of community based micro hydropower; they are all from altruism, generosity, dignity, solidarity, friendship, trust, etc., obtained from social capitals. As said by Platteau, this is also the 'moral economy' of societies characterized by kinship relations (Platteau, 1991). 
From the beginning of my more than one-month long participant observation, I had some idea about the impacts of the kinship system existing in Pokhari. In the course of the study, I came to know the reasons of successful operation of micro hydropower for more than fifteen years. The kinship organization has existed as an inevitable part of Pokhari community for the individuals' mission of micro hydropower development. So this paper not only confines the kinship within the boundary of household contexts and inspects on the basis of biological needs for making a social homogeneity but also oversees its presence in socio-cultural interrelationships. Therefore, here is some variability of the relationship between kinship and social capital for the study of social embeddedness in community development. Both social capital and kinship system are the influencing factors for making a setting of institutional culture and community transformation, mainly.

\section{Social Capital: An Indicator of Sustainability of Hydro Project}

The web of kinship is beneficial to the people of Pokhari with the notions of 'moral economy' and 'source of social cohesion' in which I will focus my discussion on it. To have the benefit to the society indicates the benefit to the 'bond nature' existing between people. This, influence and effectiveness of bond nature, has the effect on social solidarity/unity, friendship, brotherhood, sisterhood, reciprocity, generosity, altruism as well as in the social dignity and social safeguard. Besides, these are the measuring tools of social relationship and social capital. These abstract characters of cognitive variables are the immediate support and protection provided by kinship organization (Schapera, 1950). In the idiom of Schneider, it may be called 'codes for conduct' (Schneider, 1984, p. 130). Schneider's codes for conduct are components bonding with social organs and generate a 'social power or energy' that every member of the community feels secure with it. He clearly mentions the code for conduct is a set of rules, customs or traditions establishing a pattern for behavior among legal kin (Schnedier, 1984).

Radcliffe-Brown is stating 'the chief source of social cohesion is the recognition of kinship'(RadcliffeBrown, 1950:43 quoted by Schneider, 1984), however there is social capital in the intermediate, which is crucial. Therefore, in the examination of kinship organization and social capital, both are inseparable part from each other. Uphoff (1996) asserts another form of social capital, i. e. normative form of social capital which is known as social energy, they are soft variables and mainly the required knowledge is generated and maintained in individual, subjective mental processes, while being expanded and evolved in shared and collective ones.

In this connection, firstly, Hanifan analyzed the 'tangible substances that count for most in the daily lives of people, namely good will, fellowship, sympathy, and social intercourse among the individuals and families who make up a social unit' (as cited in Putnam, 2000, p. 76). Then after, Bourdieu (1984 and 1986) analyzed social obligations (connections), which are convertible into economic capital. However, Bourdieu focused on it later through the practical basis of production and reproduction of social inequality (see Bourdieu, 1984). James Coleman (1988) writes social capital is the union of different entities and it can be defined by its function.

Pokhari community itself benefited with the bilateral cross cousin marital structure for their social behavior. It has a symbiotic relationship, so no one could reject the call, proposition, advice, etc., of other to create a social cohesion for the communal advantages. A household was seen quickly ready to find the solution if other had been in the problem. During my study, various religious programmes, puja, bratabandha, wedding ceremonies and the purans were organized. In such programmes, everyone was busy from early morning to the night to perform their assigned tasks. No one has to ask them to perform their role. Their roles include the provision and management of electrical appliances, drinking water, food and lodgings for the invitees, sanitation around the organized site, etc. Such programmes were traditionally organized in the winter season since all people were in leisure time and could give abundant time for such works. In a nutshell, it is clear from the study made in Pokhari has been produced the normative forms of human qualities, such as social unity, fraternity, brotherhood, sisterhood, trust, reciprocity, etc. These all forms make Pokhari community more advantageous in every social behavior. Therefore, social capital not only reflects on social activities but also reflects over the planning and development. World Bank also announces the social capital is critical for human and economic development. The protection and strengthening of existing social capital and the promotion of new social capital should be most integral elements of poverty alleviation strategies (Grootaert and van Bastelaer, 2001). Putnam again states regarding social capital through the collective value of all social networks that brings together people who are like one another in important aspects (ethnicity, age, gender, social class, etc.) whereas bridging social capital refers to social networks that bring together people who are unlike one another (Putnam and Ghoss, 2002). After all, they all have assumed that the central features of social capital of any society e.g. solidarity, equality, trust, reciprocity, cooperation, friendship, brotherhood, etc. work as the community's strength in any of the community based institutional management. The important thing to note is that social capital is not embodied in any particular individual, but rather is embedded in people's relationship in the form of normative as well as structural state.

It is also assumed in terms of social capital from various existing studies that the influence of social capital enhances the capacity and conscience of an individual and a community while the people of various communities of a region or a society 
are also brought together in their social network by it. John Field, on the other hand, writes social capital theory is related to relationship matters and social networks, which are valuable assets. In such relationship and networks, interaction enables people to build community, to commit themselves to each other, and to knit the social fabric. Besides, senses of belonging, trust, tolerance, friendship, etc. are key of social network that bring great benefits to people (Field, 2003).

Putnam has examined social capital theory from two angles, bonding social capital and bridging social capital (Putnam, 2000). Bonding social capital entails ties between people in a similar situation, such as family, close friends, and close neighbors. On the other hand, bridging social capital entails having social contacts outside groups, or distant groups i.e. different ethnic and religious groups. This paper has relied on a homogenous social structure for the social and development achievements. The homogenous group has bonding social capital either in active social form or in passive form. On the other hand, some roles are necessary to create an environment for bridging social capital because it is not inherent like bonding social capital. The manners such as friendship, trust, exchange should be active to establish social relationship with the external groups. Putnam has found that both of these social capitals are disappearing in these days in normal social life. However, social capital exists very well particularly in homogeneous society, which is found in the rural and traditional societies like Pokhari.

From the above mentioned conceptual and ethnography analysis, it can be acknowledged that kinship system generates social capital and to some extent vice-versa. To generate social capital only is not sufficient, but also social capital must come into the actions between social organs. I have already discussed about REDP as an external force. Lets get back to the role of REDP and the concept of micro hydro scheme are the causal factors for entire structural change of Pokhari community. When these two forces entered the community, kinship found its real nature in social capital.

An instance was that about fifteen hundred people were present from both sides in a wedding ceremony of a Chaulagain boy of ward six and a Gautam girl of ward three of PokhariChaunri VDC. That was the exceptionally larger presence of people I have ever seen in the wedding ceremonies. Both the parties were well-offs of that VDC. All the people other than the close relatives of the bride were the attendants of marriage procession. The bride's relatives who had not attended the marriage procession at first were also seen to be the attendants later as they were also the invitees from groom's side. Most of them had the compulsion not to attend the marriage procession at the beginning because of the responsibility with the bride's side in addition to the long geographical distance to the groom's house than to the bride's. Sampled people said that such scene could also be seen in all other wedding ceremonies of Gautams and/or Chaulagains. The neighbors of the bride completed all the wedding feast/ party related responsibilities. It was a perfect example of social unity, fraternity, brotherhood or sisterhood and social understanding.

Such kind of social bond had helped greatly in overseeing and managing the electricity. If any electrical problem were found in any household, the technician would already be there to solve the problem. The technician had the double responsibility in such cases. Firstly, he had his job responsibility and, secondly, he might have marital or blood relation to that household since a Chaulagain had either the blood or marital relationship with a Gautam, and vice-versa. This had helped the work to be transparent, timely, qualitative, trustworthy, etc. The direct relationship prohibited them to deceive others. The committees were even more committed and responsible to the women. Women development programmes were launched for women empowerment. The institution was working to create the employment, self-employment and income generating opportunities to the women. In this course, the trainings under self-employment on beekeeping, poultry farming and making soaps, stick incense and bamboo tools helped women to earn extra income. While making bamboo tools, a person can complete one tool worth Rs. 400 only in two and a half days while taking time for the household works too. Ram Gopal Gautam, the current president of the ChaunriKhola-I MHP cooperative, said that 'the institution had the aim to empower all the women of community'.

Every community has its own familial and kinship structure. However, the geographical range of the impact of that structure on human beings is more important. The deep study of kinship structure of some communities, for instance, Newar, Dhimal, Tamang, Sherpa, Gurung, etc. can be found. However, the kinship study of higher castes, e.g. Brahman and Chhetri are insufficient. Moreover, their anthropological studies are even few. It is known from the above discussion that various familial and socio-cultural dimensions help directly and indirectly in the progress and development of a community. The dimensions, as mentioned above, include the social unity, fraternity, brotherhood, sisterhood, mutual trust, reciprocity created by kinship network. It could be clearly seen in Pokhari that ChaunriKhola-I MH was successfully operated till the study period because of direct and indirect support of fundamental social dimensions created by kinship relation. Therefore, these dimensions are termed here as the fundamental social capital.

\section{Conclusion}

A number of anthropologists have emphasized on interdependent and interconnected dimensions of sociocultural circumstance (i.e. embeddedness) and it should be considered with an anthropological lens in the development studies of community based resource management system (Fisher, 1994; Wade, 1988 and Uprety, 2008). This concept can be occurring in the collective action that appears 
in the best possible form only in the specified sociocultural milieu and provides mutual benefits. Specified socio-cultural milieu indicates the existing traditional and social institutions - marriage, family and kinship, and the responsibility of social capital also the key one. Principally, kinship organization and social capital have contributed equally in mutual benefits to the community by creating an environment of collective action. Hence, the community-based development activities are more effective and sustainable only if aforementioned social components come and work together actively. The overall social relations, behaviors and activities can be judged with these components because they are powerful social diagnostic tools of any society.

The primary condition of a sustainable community development requires an environment of institutional culture that is underpinned by an organized community, traditional (for instance kinship organization) and nontraditional (such as REDP, an NGO) organizations, and socio-cultural capital. These kind of social scenarios have an influential quality of creating the uniform society. The data presented in the analysis reports that the uniformity level of social structures and ideologies are the preconditions for development stability. Uniformity creates social equality and equitable practices in the society and such society constructs largely a social homogeneity.

Before launching any development schemes in the community level, attention should also be given on various socio-cultural milieus. For instance, before the establishment of the micro hydropower, the local people were taught to be institutional, to obey the institutional rules and regulations and to act or behave from within the institutional arrangements. It is only then that the establishing processes of micro hydropower were started. Therefore, this paper concludes that development programs should be applied only in its condition of being locally fit. Implication of institutional principles will be of no meaning and benefits for the society if the development programs are applied without the appropriate sociocultural environment.

\section{References}

Barnard A. and Spencer, J. (2010). The Routledge encyclopedia of social and cultural anthropology $\left(2^{\text {nd }}\right.$ ed.). London: Routledge.

Bennett. L.(1983). Dangerous wives and sacred sisters: Social and symbolic roles of high-caste women in Nepal. Kathmandu: Mandala Publications.

Bista, D. B. (2002). Sabaijaatko phulbari. Kathmandu: HimalKitab.

Bourdieu, P. (1984). Distinction: A social critique of the judgment of taste. Retrieved from :http:// monoskop.org/images/e/e0/Pierre_Bourdieu_ Distinction_A_Social_Critique_of_the Judgement_of_Taste_1984.p.pdf
Bourdieu, P. (1986). The forms of capital. In J. Richardson (Ed.), Handbook of theory and research for the sociology of education (pp. 241-258). New York: Greenwood.

Bromley, D. W. (1986). Closing comments at the conference on common property resource management. In Proceedings of the Conference on Common Property Resource Management, April 2126, 1985. Washington: National Academy Press.

Bromley, D.W. (1990). The commons, property, and common property regimes. Paper presented at the first annual meeting of international association for the study of common property. September 27-30, 1990. Duke University:

Bruce, J.W. (1999). Legal bases for the management of forest resource as common property. Rome: FAO.

Carsten, J. (2000). Introduction: Cultures of relatedness. In J. Carsten (Ed.), Cultures of relatedness: New approaches to the study of kinship (pp. 1-36). Cambridge University Press.

Cirivcy-Wantrup, S.Y. and Bishop, R.C. (1975). Common property as a concept in natural resource policy. Natural Resources Journal, 15, 713-27.

Coleman, S. J. (1988) Social capital in the creation of human capital. American journal of sociology, 94,95-120.

CRT/N. (2005). NGO capacity building for povertyreducing sustainable energy solutions in south Asia project. Kathmandu.

Field, J. (2003). Social capital. London: Routledge.

Fisher, R.J. (1994). Indigenous forest management in Nepal: Why common property is not a problem? In Michael Allan (Ed.), Anthropology of Nepal: Peoples, problems and processes (pp. 64-81). Kathmandu: Mandala Book Point.

Fortes, M. (1969). Kinship and the social order: The legacy of Lewis Henry Morgan. Chicago: Aldine.

Fortes. M. (1949). The Web of kinship among the Tallensi: The second part of an analysis of the social structure of a trans-Volta tribe. London: Oxford University Press.

Fortes. M. (1970). Time and social structure, and other essays. London: Athlone Press.

Franklin, S. and McKinnon, S. (2001). Relative values: Reconfiguring kinship studies. Duke University Press.

Fukuyama, F. (2001). Social capital, civil society and development: Third World Quarterly, 22(1) 7-20.

Grootaert, C. and van Bastelaer, T. (2001). Understanding and measuring social capital: A synthesis of findings and recommendations from the social capital initiative. Working Paper No. 24. World Bank.

Korten, D.C. (1990). Getting to the $21^{\text {st }}$ century: Voluntary action and global agenda. New Delhi: Oxford and IBH Publications.

Kottak, C.P. (2004). Anthropology: The exploration of human diversity. New York: McGraw Hill.

LeCompte, M. D. and Schensul, J.J. (1999) Designing and conducting ethnographic research. 
Ethnographer's toolkit, 1. California: Santa Maria Press.

Levi-Strauss, C. (1949) 1969. The elementary structures of kinship. Boston: Beacon Press.

McKean, M.A. (1996). Common property: What is it, is it good for and what makes it work? Rome: FAO

Ostrom, E. (1990). Governing the commons: Analysis of the evolution of institutions for collective action. Cambridge: Cambridge University Press.

Ostrom, E. (2000). Collective action and the evolution of social norms. The journal of economic perspectives, 14(3), 137-158.

Paxton, P. (2002). Social capital and democracy: An interdependent relationship.American Sociological Review, 67(2), 254-277.

Platteau, J.P. (1991). Traditional systems of social security and hunger insurance: Past achievements and modern challenges. In E. Ahmad, J. Dreze, J. Hills, and A. Sen (Eds.),Social security in developing countries (pp.112-170). Oxford: Oxford University Press.

Putnam, R. (2000). Bowling alone: The collapse and revival of American community. New York: Simon \& Schuster.

Putnam, R. D. and Goss, K. A. (2002). Introduction. In Robert D. Putnam (Ed.), Democracies in flux: The evolution of social capital in contemporary society (pp. 3-19). Oxford: Oxford University Press.

Read, D.W. (2007). Kinship theory: A paradigm shift. Ethnology, 46, 329-364.

Rivers, W. H. R. (1968). Social organization. London: Dawsons of Pall Mall.

Schapera, I. (1950). Kinship and marriage among the Tswana. In A. R. Radcliffe-Brown and C. D. Forde (Eds.), African systems of kinship and marriage. London: OUP for the International African Institute.

Schneider, D.M. (1984). A critique of the study of kinship. Ann Arbor: University of Michigan Press.

Schweitzer, Peter P. (2000). Dividends of Kinship: Meanings and uses of social relatedness. New York: Routledge.

Suar,D., Hota, L. Biash and Sinha, H. (2006). Nongovernmental organizations in rural development. In M.C. Behera (Ed.), Globalizing rural development: Competing paradigms and emerging realities(pp. 160182). New Delhi: SAGE publications.

Uphoff, N. (1996). Learning from Gal Oya: Possibilities for participatory development and post-Newtonian social science. London: IT Publications.

Uprety, L.P. (2008). Embeddedness and its role in irrigation management: Some anthropological observations from western Terai, Nepal. In K.N. Pyakuryal, B. Acharya, B. Timseena, G. Chhetri and M.D. Uprety (Eds.),Proceedings of the international conference on multiculturalism (pp. 259-278). Kathmandu: SASON

Wade, R. (1988). Village republics: Economic conditions for collective action in south Asia. Cambridge: Cambridge University Press.
Aryal, Rudra doing a $\mathrm{PhD}$ from Tribhuwan University (TU), Kathmandu. He has completed his MPhil degree in anthropology from TU. As a professional work experience with more than seven years in academic and non-academic institutions, he has been involved in a number of quantitative and qualitative research works. Currently, he has been working as an ethnographic researcher in a research institution conducted by Central Department of Anthropology, TU.

Email: roodraaryal@gmail.com 